2018 4th International Conference on Computer and Technology Applications, ICCTA 201827 June 2018, Pages 20-244th International Conference on Computer and Technology Applications, ICCTA 2018; Istanbul; Turkey; 3 May 2018 through 5 May 2018; Category numberCFP18P55-ART; Code 137542

\title{
Personal data protection maturity model for the micro financial sector in Peru(Conference Paper)
}

- Garcia, A. ${ }^{a}$ Email Author,

- Calle, L. ${ }^{\mathrm{a}}$ Email Author,

- Raymundo, C. ${ }^{\mathrm{a} E m a i l}$ Author,

- Dominguez, F. ${ }^{b}$ Email Author,

- Moguerza, J.M. ${ }^{\mathrm{b} E m a i l}$ Author

- View Correspondence (jump link)

- $\quad{ }^{a}$ Escuela de Ingeniería de Sistemas y Computación, Universidad Peruana de Ciencias Aplicadas, Lima, Peru

- ${ }^{\text {b} E s c u e l a ~ S u p e r i o r ~ d e ~ I n g e n i e r i ́ a ~ I n f o r m a ́ t i c a, ~ U n i v e r s i d a d ~ R e y ~ J u a n ~ C a r l o s, ~}$ Madrid, Spain

\begin{abstract}
View references (25)
The micro financial sector is a strategic element in the economy of developing countries since it facilitates the integration and development of all social classes and let the economic growth. In this point is the growth of data is high every day in sector like the micro financial, resulting from transactions and operations carried out with these companies on a daily basis. Appropriate management of the personal data privacy policies is therefore necessary because, otherwise, it will comply with personal data protection laws and regulations and let take quality information for decision-making and process improvement. The present study proposes a personal data protection maturity model based on international standards of privacy and information security, which also reveals personal data protection capabilities in organizations. Finally, the study proposes a diagnostic and tracing assessment tool that was carried out for five companies in the micro financial sector and the obtained results were analyzed to validate the model and to help in success of data protection initiatives. (C) 2018 IEEE.
\end{abstract}

\section{Author keywords}

data protectioninformation securitymaturity modelmicro financialpersonal data

\section{Indexed keywords}

Engineering Decision makingDeveloping countriesEconomicsFinanceLaws and controlled terms: legislationSecurity of data 
Engineering Assessment toolEconomic growthsFinancial sectorsInternational uncontrolled standardsMaturity modelmicro financialProcess

terms ImprovementQuality information

Engineering main
heading:

- ISBN: 978-153866995-2

- Source Type: Conference Proceeding

- Original language: English

- DOI: $10.1109 /$ CATA.2018.8398649

- Document Type: Conference Paper

- Sponsors:

- Publisher: Institute of Electrical and Electronics Engineers Inc. 